\title{
Subordinación, Flexibilización y Relaciones laborales encubiertas*
}

\author{
Añez Hernández, Carmen**
}

\section{Resumen}

A nivel mundial, se ha desatado un aumento considerable de la desigualdad social y una división del mercado de trabajo. Esto ha originado cambios en el mercado y en las relaciones laborales. Por consiguiente, se ha puesto de manifiesto la llamada flexibilización laboral en sustitución de la subordinación convirtiéndose en la antítesis del derecho laboral. De acuerdo a lo planteado el trabajo tiene como propósito describir la subordinación, la flexibilización y las relaciones laborales encubiertas. La metodología consistió en una revisión bibliográfica que permitió plasmar una opinión objetiva sobre el tema. Se puede inferir que existe una relación directa entre el decrecimiento del trabajo subordinado y el crecimiento del trabajo atípico, precario, donde el trabajador es de segunda, barato, sin ningún tipo de amparo, pero explotado al máximo, esto conduce a relaciones encubiertas de trabajo, adoptadas como estrategia empresarial, las cuales obstaculizan la relación laboral proporcionando una relación de distinta naturaleza, cuyo perfil es que el trabajador realiza ciertas jornadas sin un contrato de trabajo establecido, obviando con ello beneficios laborales.

Palabras clave: Subordinación, flexibilización laboral, relaciones encubiertas, despido fraudulento.

Recibido: 25-19-13. Aceptado: 25-19-13

* $\quad$ Este trabajo presenta resultado parciales del proyecto de investigación titulado: Relaciones laborales encubiertas implementadas por las empresas cerveceras ubicadas en el municipio Maracaibo del Estado Zulia", adscrito al Centro de Estudios de la Empresa de la Facultad de Ciencias Económicas y Sociales de la Universidad del Zulia Maracaibo- Venezuela y registrado ante el Consejo de Desarrollo Científico, Humanístico y Tecnológico (CONDES)

** Socióloga. Magíster en Intervención Social. Investigadora del Centro de Estudios de la Empresa. Facultad de Ciencias Económicas y Sociales de la Universidad del Zulia. E-Mail: carmenanez55@yahoo.com 


\section{Subordination, Flexibilization and Covert Labor Relations}

\section{Abstract}

On a world level, a considerable increase of social inequality and a division of the labor market have been unleashed. This has originated changes in the market and in labor relations. Therefore, so called labor flexibilization has come to the fore in substitution for subordination, converting itself into the antithesis of labor rights. The purpose of this study is to describe subordination, flexibilization and covert labor relations. The methodology consisted of a bibliographic review that made it possible to express an objective opinion on the topic. It can be inferred that a direct relationship exists between the decrease of subordinated work and the growth of atypical, precarious work, where the worker is second string, cheap labor with no type of protection, exploited to the maximum. This leads to covert work relations, adopted as an entrepreneurial strategy, which block the labor relation, offering a relationship of a different nature, whose profile is that the worker carries out certain days of work without an established work contract, giving up work benefits.

Key words: Subordination, labor flexibilization, covert relationships, fraudulent firing.

\section{Introducción}

De acuerdo a Ramírez (2009), la dependencia o subordinación laboral viene sufriendo alteraciones ante los cambios originados en la producción y en el mercado, conllevando a que las organizaciones acudan a la flexibilización laboral, el trabajo a distancia, la empresa virtual a través del outsourcing o tercerización, cambios tecnológicos, entre otros, impulsando la decadencia del derecho colectivo por la crisis sindical, los cambios en la negociación colectiva y las nuevas características de las tipologías de trabajo, aspectos que están produciendo modificaciones trascendentales en el derecho del trabajo ante la necesidad de reducir los costos sociales provocada por la competitividad de la globalización.

En esta perspectiva, se ha ido suprimiendo los límites entre el trabajo subordinado y el independiente. Al respec- to" Ramírez (2009:21), señala: "Hay muchas actividades que siendo trabajo personal, no quedan necesariamente calificadas como trabajo subordinado $\mathrm{y}$, por consiguiente, comprendidas en el ámbito protector del derecho del trabajo, por ser consideradas prestaciones independientes. La forma tradicional de trabajo subordinado no es la regla, sino la excepción".

Por medio de la globalización y las estrategias empresariales aplicadas por las empresas para obtener mejores beneficios a más bajo costos, se acentúa entre ellas el trabajo flexible, lo cual implica deprimir los niveles salariales y los beneficios sociales que se venían expresando como un costo laboral, forjando la precarización del trabajador, y el desconocimiento del Derecho del Trabajo por parte del patrono o empleador. Se propaga en el mercado laboral otros modelos de acondicionar los contratos de trabajo y los beneficios del trabajador representa- 
dos en el Derecho civil o mercantil, con ambos se renuncia a la obligación protectora y defensora del trabajador.

Bajo este argumento, se trata de la imposición de la voluntad de una de las partes: el patrono, quien presume de una superioridad frente a la sumisión del trabajador, quien por no quedar desempleado admite una relación laboral atípica, renunciando a los beneficios que por ley le corresponden.

Dicha situación coloca al trabajador en una dependencia directa con la precariedad y por supuesto con la inestabilidad de su puesto de trabajo. Al respecto Heery y Salmon (2011), manifiestan que la inseguridad laboral no solo presupone la pérdida del empleo, sino también afecta a la incertidumbre que puede experimentar un trabajador en sus expectativas de desarrollo de carrera, oportunidad de promoción, aumento de sueldo, participación en la discusión de contratos colectivos, entre otros aspectos referidos al trabajador.

Por lo antepuesto, se nota en cualquier tipo de empresa (pública o privada) una acentuada distorsión de la calidad y el tipo de trabajo, así como la disposición de un reconocido salario, el cual, la mayoría de las veces no es beneficio del consenso de un contrato colectivo, ni del convencimiento entre las partes. Es el empleador quien asigna de acuerdo a sus intereses las remuneraciones, asunto muy cotidiano en el sector comercio y servicios, donde se otorga al empleado un salario y condiciones de trabajo precarias, desprendiéndose del compromiso de asumir beneficios laborales, acelerando con esto los empleos temporales.

En concordancia a lo esbozado se puede inferir que existe una relación directa entre el decrecimiento del trabajo subordinado, la inestabilidad del trabajo conducente al desempleo y el crecimiento del trabajo atípico, precario, donde el trabajador es de segunda, barato, sin ningún tipo de amparo, y explotado al máximo. Lamentablemente, esto representa la salida del trabajador para poder sobrevivir, lo cual no mejora de acuerdo al aumento o aceleración de la economía, por el contrario, este tipo de relación laboral distanciada del Derecho del Trabajo se está transmitiendo y aplicando en casi todo los sectores por sus bajos costos, enmascarando las relaciones laborales.

Con base a lo señalado, el artículo bajo una óptica teórica pretende describir la subordinación, la flexibilización y las relaciones encubiertas de trabajo. Aspectos relevantes que vienen distorsionando las relaciones laborales. Para tal fin se realizó una revisión bibliográfica que permitió extraer y plasmar un conjunto de autores que sustentan estos tres aspectos, lo cual permitió emitir una opinión objetiva sobre el tema.

Se diserta sobre la subordinación como elemento fundamental para demostrar la inserción de un trabajador en una relación laboral, se plantea la sustitución de la subordinación por la flexibilización, resaltando las formas de flexibilización laboral más utilizadas, con las cuales se reducen los beneficios laborales precarizando a los trabajadores.

De igual forma se plantea las relaciones encubiertas y despido fraudulento como una forma de dar a conocer cómo estas relaciones trastocan el principio de continuidad del trabajo; el trabajador se enmarca en una relación laboral atípica que deteriora sus beneficios, quedando sujeto a lo señalado en la ley mercantil o civil. 


\section{La Subordinación}

La subordinación, es un elemento esencial en una relación laboral, la presencia de este hecho es apta para manifestar y demostrar que el trabajador que está inserto en una relación laboral. Es necesario plantear que la subordinación, es la autoridad que tiene un patrono o contratante, de suministrar decisiones y órdenes a sus contratados, de ubicar su fuerza de trabajo según sus instrucciones, necesidades y conveniencias.

Por consiguiente, el trabajador al asumir y ejecutar los dictámenes e instrucciones del patrono, se cristianiza como un trabajador subordinado. Granados (2013), señala entre otros aspectos que la subordinación se expresa en la obligación de cumplir un horario, debe pedir permiso para salir del trabajo en el horario establecido o para faltar a él, realizar las tareas señaladas, entre otras, lo que confirma que estamos frente a una subordinación. Si no fuese de esta forma, el trabajador podría disponer de su tiempo según su conveniencia, siempre y cuando, cumpla con el objeto del contrato si este fuera de servicios.

En este orden de ideas, Ramírez (2009: 32), señala un conjunto de indicadores que caracterizan la subordinación, tales como "la relación jerárquica, la sujeción a la función organizadora y directiva del titular y a la actividad propia de la empresa, las órdenes e instrucciones a la voluntad prevaleciente del empleador, la dirección y control y el ejercicio del poder disciplinario y sancionador por quien proporciona el trabajo, así como el marco reglamentario interno, la prestación diaria, la disponibilidad personal".
Lo anterior, se convierte en la autoridad que tiene el patrón de dar instrucciones a un empleado, en el sentido de marcar la forma y términos en que deben desarrollarse sus actividades, es decir, indicarle el lugar de trabajo, la jornada laboral, proporcionarle instrumentos y herramientas necesarias además de señalarle los métodos, técnicas y procedimientos de cómo realizarlo; existiendo por parte del trabajador la obligación de cumplir con estas instrucciones.

Así, se puede decir de acuerdo a Flores (2008), que la subordinación caracteriza la relación laboral, sirviendo para distinguir el contrato de trabajo de cualquier otro tipo de contratos de prestación de servicios profesionales

Evidentemente, la subordinación entraña, para el patrón dos potestades: 1) la de mando y, 2) la obediencia del trabajador. Esto significa que de acuerdo a la subordinación el patrón tiene la facultad de ordenar, y el derecho a ser cumplida dicha orden por el trabajador. La obediencia implica ejecutar en una relación de trabajo, lo previamente negociado realizar durante la jornada laboral, fuera de estos argumentos, todo mando por parte del patrono hacia el trabajador es ilegal. El vínculo establecido de subordinación es sólo funcional, es decir, la ejecución de trabajo no puede ir más allá de lo convenido.

Es así como la subordinación según Escalona (2008), se constituye en el elemento característico de la relación de trabajo, pues para que se dé este vínculo es necesaria la subordinación. Esta permite diferenciar cualquier otro tipo de prestación de servicios, como serían los profesionales prestados de manera inde- 
pendiente, sin dirección ni dependencia de otro, tal cual sería el caso cuando se contratan servicios profesionales.

La dependencia o subordinación han venido sufriendo cambios de enfoque de acuerdo a la modernización o exigencias del mercado para lograr mayor cobertura y competitividad. Es por eso que se han transformado las relaciones con el trabajador y las formas de contratación laboral, instaurando diferentes criterios para declinar la subordinación.

En este sentido, Ramírez (2009) identifica los criterios utilizados para excluir la subordinación de la siguiente manera: utilización de medios de producción propios, uso de servicios de terceros, percepción no salarial, organización autónoma y la no sujeción a órdenes o instrucciones, así como la ausencia de controles, posibilidad de sustituir al prestador del servicio, prestación del servicio o la ejecución de la obra por cuenta e interés propio, no exclusividad y la temporalidad, entre otros

En definitiva, el trabajo subordinado y dependiente es aquel que se presta bajo un contrato de trabajo entre un trabajador y un empleador, quien se compromete a cumplir los beneficios laborales correspondientes en su empresa y bajo la autoridad de éste, durante la jornada legal de trabajo, desempeñando labores que por contrato se ha comprometido a ejecutar. Esto implica que el trabajador pierde su independencia; sólo la rescata cuando finaliza la jornada de trabajo.

A pesar que el Derecho del Trabajo surge para proteger al trabajador desde el punto de vista económico y social, Castillo (2010), señala que el derecho del trabajo no se ocupa de tutelar y mejorar las condiciones y los derechos de los trabaja- dores subordinados o dependientes, sino de la defensa de la propiedad privada, la que se acrecienta con la plusvalía arrancada de los trabajadores.

Por ello, para Pérez (2008), la situación merece repensar el tema de la subordinación o dependencia de una manera creativa para buscar una solución a lo que, a pesar de ser un avance incontenible, antiprotector, no impide buscar alternativa que permita la continuidad de la misión principal del derecho del trabajo: restringir o limitar el poder jerárquico del empleador para evitar que el poder de dirección se convierta en abusivo.

En atención a lo planteado, Rodríguez et al (2009:212), señalan que "el trabajador subordinado representó a finales del siglo XIX y principios del XX, la hegemonía social, reclamando una intensa tutela normativa. En tal sentido, la protección de la clase trabajadora constituyó durante los citados siglos, un sinónimo de protección y promoción de los despedidos y los más necesitados"

Los cambios vistos en la realidad laboral dominan la subordinación; se conserva el control absoluto del contratante sobre el trabajador, no siendo entonces tan importante la protección laboral estatuida en los contratos colectivos y la Ley del trabajo.

\section{Sustitución de la subordinación: la flexibilización}

Los mercados laborales aparecen como una condición esencial para facilitar y adaptar el cambio estructural y las nuevas visiones de las economías, en tal sentido, las empresas deben amoldarse a los cambios para poder subsistir y competir 
en el mercado, de ahí la importancia de la implantación de la flexibilización laboral.

La flexibilidad laboral, se propone e impone con el objetivo de ser identificada con políticas deliberadas de reducción de beneficios laborales de los trabajadores. Por ello resulta pertinente considerar todas las formas que puede asumir la flexibilidad laboral.

En cada empresa, la flexibilidad laboral constituye sólo un aspecto formalizado por la globalización, la cual debe ser asumida y posesionada, a fin de poder generar nuevos productos al mercado nacional e internacional, externalizar las empresas en los mercados competitivos, gracias a la disminución de salarios y beneficios laborales que permiten invertir en otras áreas rentables de la empresa.

Existen diversas formas de flexibilización laboral, entre las cuales se pueden mencionar en términos muy generales las siguientes:

- Flexibilidad externa: "esta forma de flexibilidad tiene por objeto variar el número de trabajadores de acuerdo con las necesidades del proceso productivo. Se contrapone con el tema de la seguridad y protección del empleo, ya que estos factores representan la mayor restricción a la posibilidad de lograr este tipo de flexibilidad" (González, 2010:34).

- Flexibilidad interna: dentro de la flexibilidad interna, según González (2010), se encuentra la funcional que significa para el trabajador la modificación de las tareas según las necesidades de la empresa y las exigencias del mercado. Este tipo de flexibilidad no altera el número de trabajadores, ya que existe la independencia para ajustar y redistribuir el número de horas trabajadas de acuerdo con las necesidades de la producción. Esto ha acontecido debido a la introducción de nueva tecnología necesaria para el reajuste y celeridad que deben tener los procesos productivos.

Las empresas determinan al trabajador el número de horas a cumplir en cada proceso, esfumándose las horas extras trabajadas sin ser remuneradas. El efecto ha sido la aparición de trabajadores sin horario fijo, multifuncionales y polivalentes con dominio de todo el proceso, con lo cual desaparece la especialización.

\section{- Flexibilidad de los salarios y los cos-} tos laborales: el objetivo es constreñir los tipos de remuneración del trabajo sujetas a la categoría ocupacional y a las escalas de antigüedad para encontrar nuevas variantes de pago relacionadas con indicadores de desempeño.

De acuerdo a González (2010), estas formas de pago encadenadas con las destrezas y experiencias del trabajador apuntan a lograr el ajuste de las empresas con las exigencias del mercado.

Parece claro que la adopción de éstas por los trabajadores implica que las negociaciones salariales se realizan fuera de contratos colectivos o los sindicatos y por ende, sin tomar en cuenta el derecho del trabajo, sino el mercantil o civil.

- Flexibilización el trabajo a distancia: de acuerdo a Gómez (2011), el mejor ejemplo de este tipo de flexibilización es el teletrabajo, que está destruyendo puestos de trabajo, reduciendo y eliminando los costos laborales por parte de empresas. 
El sector servicio es donde más se utiliza este tipo de flexibilización, con esta desaparece el contrato fijo y, por ende, crece la explotación del trabajador por no tener horario de trabajo, la empresa no proporciona las herramientas de trabajo, el trabajador debe poseerlas tanto materiales como intelectualmente para ser contratado, ya que lo fundamental para la empresa contratante es el conocimiento.

Por otra parte, la necesidad de reducir los costos sociales provocados por la competitividad explica la aparición de la empresa virtual a través del outsourcing o tercerización de servicios, esta es una de las estrategias más comprometida con las necesidades del mercado global.

Aparece en el mundo globalizado la Empresa Virtual, que según Ronel (2010:34), "es una estructura organizativa que responde a las necesidades del mercado actual con mayor facilidad que otras estructuras tradicionales, debido a su facilidad de adaptación y utilización de las Tecnologías de la Información de forma intensiva."

En una empresa virtual no es importante en donde se encuentre el trabajador ni la empresa. La resolución del proceso es más eficiente y eficaz, lo que permite contribuir con la complacencia del cliente, ya que en tiempo real posibilita el crecimiento de la producción y distribución del producto; reduce los costos de producción y ubicación del producto en tiempo récord en el mercado.

Este tipo de empresa por constituirse bajo formas o estrategias tales como alianza estratégica, joint venture, outsourcing, entre otras, llegan a tercerizar la contratación de la fuerza de trabajo, lo cual disminuye los beneficios laborales y el trabajo estable. Sólo interesa estar acorde a las tendencias del mercado mediante mecanismos que le permiten extraer información sobre los requerimientos de la clientela que adquiere sus productos y/o servicios para de esta manera lograr una compraventa personalizada para cada uno de sus clientes.

En consonancia a lo esbozado, Añez (2012: 165), afirma que se presenta una nueva forma de organización empresarial que implica "flexibilizar la organización del trabajo, estableciendo una cierta tipología que permita la caracterización adecuada del trabajo con los requerimientos de la empresa inserta en el mundo globalizado, en este contexto se procede a un nuevo tipo de contratación, y por ende, de relación laboral".

Dicho reordenamiento conduce a un nuevo tipo de flexibilización expresada a través de un tipo de contrato conocido como subcontratación. De acuerdo a Ermida y Colotuzzo (2009), la subcontratación consiste en la contratación externa de cualquier tipo de actividad que anteriormente era desarrollada dentro de la estructura de la empresa, estas se externalizan, es decir, pasan a ser realizadas en el exterior de la empresa por terceros.

Puede señalarse que en la subcontratación implícitamente subyacen dos elementos clave como son: 1) el carácter espacial, debido a que se contratan empresas o trabajadores externos para realizar determinada actividad en cualquier parte del mundo y 2) la temporalidad, ya que las acciones realizadas por trabajadores o empresas son transitorias.

Bajo este enfoque se busca una forma de relación de trabajo distinta de la tradicional o normal, conformándose una 
forma de relación de trabajo atípica, regulada y excluida de las labores inherentes a la producción principal y permanente de la empresa, así como de las labores de reparación o manutención habituales de los equipos.

En ese sentido, las empresas se adjudican la potestad de regular y centralizar la contratación laboral, la política salarial, la organización del trabajo y el tiempo de trabajo, entre otros aspectos laborales.

Con base a lo señalado, puede inducirse que la demanda de flexibilidad laboral procede de la necesidad de que las empresas se adapten a los requerimientos del mercado global, promovido por la incorporación de tecnología de avance que requiere de una fuerza de trabajo adaptable y polifuncional que beneficie discrecionalmente y con decisión el desempeño de las actividades, a fin de que la empresa se mantenga en el mercado y logre su competitividad.

Sennet (2006), al respecto plantea que las organizaciones necesitan personal polivalente, abierto y flexible. Para la empresa el trabajador mejor valorado es el que está al corriente de los cambios y adecuaciones de los nuevos procedimientos productivos.

De ahí que los empleados actuales perciban la flexibilización como un peligro hacia sus puestos de trabajo, donde todo está en manos de su nivel de adaptación y conocimiento. Es por eso que no puede concluirse que la flexibilización sea una alternativa válida para los trabajadores, ya que ha generado desempleo y distorsión de las relaciones laborales.

Se explica así, como la clase trabajadora enfrenta la merma de sus derechos, de empleos estables, de condicio- nes de trabajo decente y de calidad de vida, lo cual es acompañado por la impunidad para quienes vulneran las leyes laborales. Pareciera, que el trabajo y el empleo estable no son fenómenos del nuevo proceso económico globalizado. Prevalecen como estrategias empresariales tanto la flexibilidad organizacional y laboral, ambas con la finalidad de deslastrarse de las normas protectoras y garantías de los trabajadores.

\section{Relaciones encubiertas y despido fraudulento}

El anterior esbozo referido a la flexibilización laboral conduce a reflexionar sobre las relaciones encubiertas y como éstas llevan al contratante a despedir a su antojo o interés al trabajador cuando ya no es necesario en la empresa.

En la economía mundial se ha extendido el régimen de prestación de trabajo adecuado a las relaciones encubiertas o fraudulentas. Dichas relaciones presentan tipologías esenciales en cuanto al tipo de trabajo, el cual queda evidentemente excluido de su ámbito de aplicación del derecho laboral, quedando de acuerdo a los intereses de las empresas y del mercado inserto en otras disciplinas jurídicas, tales como la mercantil y civil. En ambas el trabajador presta sus servicios en condiciones de independencia, no sujetos a la subordinación laboral.

Con la aplicación de estas leyes el principio de continuidad de la relación laboral se trunca, al trabajador se le establecen una serie de reglas representadas en una relación laboral atípica que deteriora sus beneficios, quedando sujeto a lo señalado en la ley mercantil o civil. Sin 
duda se trata de prácticas sumamente desfavorables de los derechos laborales que se aprovechan de la posición de franca desigualdad en la que se encuentran las personas trabajadoras en el marco de la relación laboral.

Desde la disposición de las relaciones encubiertas, se produce la desprotección de los derechos laborales, el cual es un tema transcendental en cualquier sociedad. Cabe considerar de manera especial, como plantea Sánchez (2011:16): "cuando se trata de la extinción del vínculo de trabajo, ya que la controversia y las posiciones encontradas son moneda corriente, no existiendo una armonía absoluta en ese sentido; el proceso laboral debe mostrarse como un mecanismo de protección idóneo cuando se ha sido víctima de un despido fraudulento".

En concordancia a lo indicado, Romero (2008), define las relaciones encubiertas como el acto mediante el cual un empresario o patrono, sea este privado o público -el Estado-, incurre en lo que se conoce como fraude laboral y, que el mismo adquiere la forma de relaciones laborales encubiertas, sin ningún tipo de apego al clásico e histórico contrato de trabajo. Constituye una de las alteraciones más notorias de los últimos tiempos en el mundo del trabajo.

De lo anteriormente expuesto se puede deducir que se está conduciendo al despido injustificado o fraudulento, que según Sánchez (2011:4), es, "aquel acto ilícito laboral, en que el empleador decide dar término a la relación de trabajo con el trabajador, basándose en una supuesta causa justificante y cumpliendo aparentemente el procedimiento establecido por la normatividad jurídica, pero que realmen- te no corresponde con el motivo real de la decisión", pero en la realidad se presenta un hecho fraudulento, forzando negativamente la dignidad del trabajador y trastocando negativamente sus remuneraciones laborales.

Con referencia a lo planteado se puede inducir que la estrategia de la flexibilización laboral se está instaurando a gran velocidad en las empresas, para tal efecto, se reforman las normas legales que rigen las relaciones laborales, las cuales permiten ocultar o encubrir una relación laboral precaria, abriendo importantes espacios para formalizar contratos atípicos, que potencian la gestión moderna de talento humano, institucionalizando una relación laboral triangular, disfrazada o encubierta y por ende despidos fraudulentos.

En este sentido, generalmente el contratante acude a acciones aparentes o imaginarias incriminadas al trabajador, con el fin de conquistar su despido (Sánchez, 2011), en los siguientes términos:

\section{a. Imputación al trabajador de hechos} notoriamente inexistentes: Se ocasiona cuando se despide al trabajador atribuyéndole de haber realizado acciones que lesionan al empleador, pero en realidad el trabajador no las ha perpetrado.

b. Imputación al trabajador de hechos notoriamente falsos: Se produce cuando se despide al trabajador inculpándolo de alguna circunstancia falsa que aparentemente deteriora la imagen del patrono o empresa, es decir que es contrario a la verdad.

c. Imputación al trabajador de hechos notoriamente imaginarios: Se origina cuando el empleador despide al trabajador imputándole haber 
realizado palpablemente hechos dañosos que se encuentran dentro de la esfera de la fantasía.

Con base a estas afectaciones originadas por el empresario para terminar la relación laboral, Romero (2008: 75), señala que los empresarios o contratantes "abrumados por el discurso globalizador, se dedicaron a denigrar de las leyes laborales, argumentando que estas no encajaban dentro de las dinámicas de la competitividad y dimensión que adquirían las empresas frente a una nueva división técnica internacional del trabajo. Había que flexibilizar la relación Capital - Trabajo, insistían los defensores del libre mercado".

Desde esta óptica se puede manifestar el punto de vista que viene dominando al mercado laboral que de acuerdo a las acciones implementadas por las empresas, capital o contratante, están conduciendo a la extinción del trabajo fijo y decente, precarizando al trabajador.

\section{Conclusiones}

Analizando sucintamente cada una de las tres posturas presentadas sobre subordinación, flexibilización y relaciones encubiertas, se percibe que las sociedades y el mercado están dominadas por la globalización, dicha dominación manifiesta diferentes estrategias con el fin de que las empresas reduzcan costos, amplíen su mercado y logren la competitividad. Es por ello que las relaciones laborales se perturben y el trabajador se presente como el eslabón más débil de la cadena organizacional y del proceso. Quedan enmarcado por el modelo social y económico impuesto en la corporación y el mercado, con el propósito de ir ajustando la mano de obra a los requerimientos del mercado. Esto implica flexibilizar los contratos de trabajo aplicando contratos atípicos alejados de las leyes y normativas que amparaban al trabajador socio-económicamente, sus condiciones de trabajo, tiempo de trabajo, entre otros aspectos.

Dichas exigencias propiciadas por el mercado globalizado son aceptadas por las organizaciones y las sociedades bajo la creencia que distanciándose de las normas establecidas y adoptando otras leyes como la mercantil o civil, apuntan hacia la apertura del mercado nacional creando nuevas fuente de empleo, ampliación de sus mercados y competencia de sus productos

En cuanto a la subordinación, se puede concluir que el patrono mantiene una serie de derechos sobre el trabajador, basado en relaciones legales que lo autorizan para instaurar su propia voluntad y velar porque el compromiso del trabajador se cumpla a cabalidad.

En la subordinación, la autoridad de mandar y la obligación de obedecer del trabajador están delimitadas e íntimamente relacionadas constituyéndose en la finalidad que persigue la relación de subordinación para el patrono como es su autoridad de mando en el trabajo, según los requerimientos del mercado y de la competencia. Dicha relación entre patrono $y$ trabajador se formaliza en un contrato de trabajo personalizado, que por lo general trasgrede la independencia del trabajador, ya que no puede distanciarse de lo convenido y desempeñar todo lo acordado por el patrono.

Con las nuevas imposiciones de la globalización y las nuevas tendencias del mercado, la subordinación como prototi- 
po del trabajo fijo comienza a hacer inhabilitado, ya que el trabajador es oneroso ante las nuevas pautas del mercado. Deja de percibir los beneficios que lo ampara la ley del trabajo y es regido por leyes mercantiles observándose el trabajador como una mercancía.

En este sentido, la flexibilidad laboral se convierte para el empresario en el ideal debido a su nueva forma de competir y expandirse, ya que la relación basada en la subordinación es considerada arcaica, obsoleta e inflexible, características que afectan la nueva visión del mercado.

Desde esta perspectiva, se defiende flexibilizar las relaciones laborares y de trabajo, de allí la puesta en práctica de trabajos a destajos, por objetivos, por proyectos, entre otros. No existen contratos laborales donde se especifiquen los beneficios, tiempo de trabajo, condiciones de trabajo, duración del contrato, así como entre otros aspectos laborales; esto contribuye a que el trabajador además de la desprotección de la cual es esclavo, sea despedido cuando termine su ocupación dentro o fuera de la organización. Sin embargo de acuerdo a su desempeño puede convenir un nuevo contrato en las mismas condiciones sin convertirse en una relación fija o estable, contrato aceptado por el trabajador para no quedar desempleado.

Es necesario resaltar que la flexibilización laboral a través de la subcontratación tiene acogida en el mercado, pero en algunos países no está formalmente institucionalizada, sino que aparece encubierta en la mayoría de las legislaciones laborales latinoamericanas. Venezuela es uno de los países que se ha pronunciado en contra de la tercerización o subcontratación. Para tal fin se reformula la Ley del Trabajo titulada Ley Orgánica del Trabajo, los Trabajadores y las Trabajadoras, promulgada en el Decreto 8938 , del año 2012, en la cual se prohíbe como forma de contrato la tercerización, tipificado en el artículo 48 y en sus literales a, b, c, d y e, en los cuales se expresa la concepción del Estado en cuanto a la protección de los trabajadores, recordando al patrón la aplicación de la Ley del Trabajo, como una forma de erradicar la disfraz o fraude laboral

Mientras Venezuela libra esta lucha, en el mercado globalizado se propicia la desregulación de la legislación laboral, es decir los gobiernos que se abren ante el neoliberalismo como forma de atraer capital aceptan e imponen las condiciones del capital extranjero y del mercado derogando la estrategia protectora de la negociación colectiva, única acción que permite salvaguardar los beneficios del trabajador.

En correspondencia con lo planteado se puede desprender que a través de la flexibilidad laboral, generalmente los países alteran las normas legales que rigen las relaciones laborales, ocultando y encubriendo una relación laboral precaria, que potencia una gestión laboral que institucionaliza una relación laboral disfrazada o encubierta, a través de la subcontratación formalizando los intereses del contratante.

En consecuencia, los derechos de los trabajadores no se relacionan con lo determinado en la ley del trabajo que es la normativa que tutela la relación laboral en cualquier país y propicia el contrato colectivo, en el cual se tipifica en base a acuerdos entre el empresario y sindicato los beneficios socioeconómicos que gozaría el trabajador. 


\section{Referencias Bibliográficas}

Añez Hernández, Carmen (2012). Subcontratación y triangulación laboral: relaciones encubiertas. En Revista Venezolana de Análisis de Coyuntura, 2012, Vol. XVIII, No. 2 jul-dic, pp. 163-177. Venezuela,

Castillo Reinoso, Carlos (2010). Derecho del trabajo, panorama y tendencias. En Revista ALEGATOS № 74 Enero-Abril 2010 pp 12-24. México

Escalona Hernández, María (2008). Subordinación características de la de la relación de trabajo. En Etiqueta Laboral. pp 34-45. Venezuela

Ermida Uriarte, Oscar y Colotuzzo, Natalia (2009). descentralización, tercerización y Subcontratación, OIT, Primera Edición, Uruguay.

Flores, Baltasar Cavasos (2008). 35 lecciones de derecho laboral. Editorial Trillas, pp 150. Venezuela

Granados, Paola (2013). La subordinación como elemento esencial del contrato de trabajo. En http://www.gerencie.com/la-subordinacion-como-elem ento-esencial-del-contrato-de-trabajo .html. Fecha de consulta 11-08-2012

Gómez, Alfonzo C. (2011). El teletrabajo en buenos aires. Argentina
González Salomón (2010). La flexibilidad laboral En Revista Educación. № 6, pp 23-34. Buenos Aires.

Heery, E. y Salmon, J. (2011). Encuesta de población activa. INE. Instituto Nacional de Estadística. London: Routledge

Pérez Albela, Alfonso de los Heros (2008). Subordinación y dependencia. Publicado en el Boletín de Derecho Comparado de la UNAM. pp.13-30. México.

Ramírez, Erendira (2009). Prestador de servicio ¿subordinado o independiente? UNAM. México.

Rodríguez G., Rosiris C.; Pernía Nuvia H. y Montilla R., Leticia C. (2009). El contrato de trabajo y la relación de trabajo: tendencias jurisprudenciales. En Revista de la Facultad de Ciencias Jurídicas y Políticas №5, 2009. pp. 217-268. Venezuela.

Ronel, Nevarez (2010). ¿Qué son las empresas virtuales? En negocios. Bookmark the link. Venezuela.

Romero Milano, Antonio (2008). Relaciones laborales encubiertas en venezuela En Revista Compedium № 20 pp. 7387. Venezuela.

Sánchez Ferrer, Luis Manuel (2011). El despido fraudulento en el régimen laboral privado ante el proceso laboral. Peru.

Sennet, R. (2006). La cultura del nuevo capitalismo. Barcelona: Anagrama. España. 